\title{
Comorbid Persistent Lower Respiratory Symptoms and Posttraumatic Stress Disorder 5-6 Years Post-9/1 1 in Responders Enrolled in the World Trade Center Health Registry
}

\author{
Stephen M. Friedman, MD, MPH, ${ }^{1}{ }^{*}$ Mark R. Farfel, ScD, ${ }^{1}$ Carey B. Maslow, DrPH, ${ }^{1}$ \\ James E. Cone, MD, MPH, ${ }^{1}$ Robert M. Brackbill, PhD, MPH, ${ }^{1}$ and Steven D. Stellman, PhD, MPH ${ }^{1,2}$
}

\begin{abstract}
Background Co-occurrence of lower respiratory symptoms (LRS) and posttraumatic stress disorder (PTSD) has been increasingly recognized among responders and survivors of the World Trade Center (WTC) disaster. Information is limited on the degree which comorbidity intensifies symptoms and compromises quality of life across exposed groups. Methods Among responders who completed the first and second Registry surveys, measures of respiratory illness, psychological distress, and diminished quality of life were compared between responders comorbid for LRS and PTSD and responders with only LRS or PTSD.

Results Of 14,388 responders, $40 \%$ of those with LRS and 57\% of those with PTSD were comorbid. When demographic and WTC exposure-related factors were controlled, comorbid responders compared to those with LRS alone were twice as likely to have frequent dyspnea and to have sought care for dyspnea. Compared to responders with PTSD alone, comorbid responders were 2.1 times more likely to report intense re-experiencing of the disaster, 2.5 times more likely to express feelings of significant non-specific psychological distress, and 1.4 times more likely to have received mental health care. Comorbid responders were approximately three times more likely to report only fair or poor general health and more than twice as likely to report being unable to perform usual activities for $\geq 14$ of 30 days before interview.

Conclusions Outcomes in comorbid responders were similar to or more severe than in comorbid survivors. Health care and disaster relief providers must suspect comorbid illness when evaluating responders' respiratory or mental illnesses and consider treatment for both. Am. J. Ind. Med. 56:1251-1261, 2013. (C) 2013 Wiley Periodicals, Inc.
\end{abstract}

KEY WORDS: comorbidity; disaster response; longitudinal study; mental health; posttraumatic stress disorder; respiratory illness; World Trade Center

${ }^{1}$ Division of Epidemiology, New York City Department of Health and Mental Hygiene, World Trade Center Health Registry, Long Island City, New York

${ }^{2}$ Department of Epidemiology, Mailman School of Public Health, Columbia University, New York, New York

Contract grant sponsor: CDC-NIOSH; Contract grant numbers: 2U500H009739; 1U500H009739; Contract grant sponsor: CDC-ATSDR; Contract grant number: U50/ ATU272750; Contract grant sponsor: CDC-NCEH; Contract grant sponsor: New York City Department of Health and Mental Hygiene (NYCDOHMH).
Theauthors wish to express their thanks to Dr.Sukhminder Osahan for his careful review of the manuscript, to Drs. Carolyn Greene and James Hadler for their thoughtful review and editing, and to Ms. Margaret Millstone and Ms. Rhoda Schlamm for their precise editing. Disclosure Statement: The authors report no conflicts of interests.

${ }^{*}$ Correspondence to: Dr. Stephen M. Friedman, MD, MPH, New York City Department of Health and Mental Hygiene, World Trade Center Health Registry, 42-09 28th Street, 07-127 Long Island City, NY11101. E-mail: sfriedm2@ health.nyc.gov Accepted 20 May 2013

DOI 10.1002/ajim.22217. Published online 21 June 2013 in Wiley Online Library (wileyonlinelibrary.com). 


\section{INTRODUCTION}

Exposure to the World Trade Center (WTC) disaster has been associated with adverse respiratory and mental health outcomes in rescue and recovery workers [Brackbill et al., 2009]. A history of lower respiratory tract symptoms (LRS) of wheezing, persistent cough, and shortness of breath has been consistently and widely reported by $9 / 11$ responders [Perlman et al., 2011]. LRS, pulmonary function test abnormalities, and diagnosed asthma and chronic bronchitis have been linked to being caught in the cloud of dust from the WTC Towers' collapse, arrival on or immediately after $9 / 11$, and longer duration of work at the site [Banauch et al., 2006; Herbert et al., 2006; Wheeler et al., 2007; Brackbill et al., 2009]. Post-9/11 onset of symptoms of posttraumatic stress disorder (PTSD), depression, and generalized anxiety disorder were also closely correlated with WTC exposures [Galea et al., 2002; Gross et al., 2006; Perrin et al., 2007; Farfel et al., 2008; Stellman et al., 2008; Berninger et al., 2010; Cukor et al., 2011].

Psychological stress and physical illness have been shown to be interrelated in clinical, physiologic, and epidemiologic studies [Wright et al., 1998; Wagner et al., 2000; Weisberg et al., 2002; Blechert et al., 2007; Dirkzwager et al., 2007]. Co-occurrence of mental and physical illness following exposure to the WTC disaster has increasingly been documented in firefighters and other rescue/recovery workers (responders) and in area workers and residents (survivors) [Gross et al., 2006; Jordan et al., 2011; Li et al., 2011; Wisnivesky et al., 2011; Luft et al., 2012; Nair et al., 2012]. PTSD was a significant predictor of self-reported moderate to severe asthma symptoms, seeking care for asthma at an emergency room, and unscheduled physician visits for asthma since 9/11 [Fagan et al., 2003]. WTC cough syndrome and PTSD symptoms were moderately associated in NYC firefighters, even after accounting for exposure cofactors [Niles et al., 2011]. PTSD statistically mediated the link between exposure and comorbid respiratory symptoms among WTC rescue, recovery, and cleanup workers [Luft et al., 2012].

The compounding effect of comorbid LRS and PTSD on reported symptom intensity and diminished quality of life was demonstrated among survivors enrolled in the WTC Health Registry [Nair et al., 2012]. Survivors comprised area workers who had a usual workplace south of Chambers Street in lower Manhattan and were present south of Canal Street between the first attack and noon on 9/11, residents who lived in lower Manhattan south of Canal Street, and passersby who were in lower Manhattan during the attacks but were not area workers, residents, or involved in the rescue and recovery effort. Survivors with LRS and PTSD were more likely to seek treatment for shortness of breath or wheezing than those with LRS alone. Survivors with PTSD and LRS experienced more symptoms of PTSD and had more severe illness than those with PTSD alone. Those with comorbid LRS and PTSD had worse quality of life and more unmet healthcare needs than those with either condition alone.

Since the duration, intensity, and range of 9/11-related exposures of responders differed from those of survivors [Brackbill et al., 2009], the effect of these exposures on comorbid respiratory and mental health symptoms in responders warrants separate examination. Furthermore, although the co-occurrence of respiratory symptoms and PTSD in responders has been well documented [Niles et al., 2011; Luft et al., 2012], data are lacking on how the presence of both of these conditions affects the manifestations of each illness and quality of life. Building on the analysis of Nair et al. [2012], this study of responders sought to determine the effect of WTC exposures on the prevalence of comorbid illness among responders with either LRS or PTSD; evaluate the impact of comorbid illness on the prevalence of reported symptoms, physician diagnosed conditions, and quality of life; and compare the compounding effects of comorbidity in responders with those found in survivors.

\section{MATERIALS AND METHODS}

The Registry comprises residents, area workers, passersby, and rescue/recovery workers exposed to the disaster on 9 / 11/2001 and its aftermath [Farfel et al., 2008]. Individuals were solicited from lists of potentially exposed adults provided by employers and government agencies (listidentified) or enrolled through an outreach and media campaign (self-identified). A total of 68,444 adults responded to the first Registry survey (Wave 1 or W1) from 2003 to 2004 , and $46,602(68.1 \%)$ of these responded to the second Registry survey (Wave 2 or W2) from 2006 to 2007 [Nair et al., 2012]. The Institutional Review Boards of the New York City Department of Health and Mental Hygiene and the Centers for Disease Control and Prevention approved the Registry protocols.

\section{Study Sample}

Adult responders in the Registry were defined as workers or volunteers 18-64 years of age on 9/11/2001 who reported being involved in rescue, recovery, cleanup, or other activities at the WTC site for at least one shift between September 11, 2001 and June 30, 2002 and participated in W1 and W2 $(\mathrm{n}=21,046)$. In order to focus on illness more likely to be attributable to WTC disaster exposures, only responders with symptom onset or disease diagnosis post-9/11 were included. Responders who reported a pre-9/11 history of persistent cough, wheezing, or shortness of breath, pre-9/11 diagnosed chronic respiratory disease (asthma, reactive airways dysfunction syndrome [RADS], or chronic bronchitis) or pre-9/ 11 diagnosed PTSD, depression, or generalized anxiety were 
excluded, leaving a total of 14,867 responders. Also excluded were 479 responders who met the screening criteria for PTSD at W1 but not at W2. The final sample numbered 14,388.

\section{Analysis Variables}

LRS was defined as reported post-9/11 onset of persistent cough, wheezing, or shortness of breath at W1 and reported experiencing of the same symptom for at least 8 of the 30 days prior to answering W2 [Friedman et al. online data supplement, 2011; Global Initiative for Asthma, 2011]. PTSD was defined conservatively based on $\mathrm{W} 2$ responses as both (a) scoring 44 or higher on the PTSD checklistCivilian Version (PCL) with questions specific to WTC experiences; and (b) reporting the moderate or greater presence of at least one re-experiencing symptom ([American Psychiatric Association, 2000] DSM-IV criterion B), three avoidance or numbing symptoms (criterion $\mathrm{C}$ ), and two hyperarousal symptoms (criterion D) [Blanchard et al., 1996; Ruggiero et al., 2003].

Demographic variables included age on 9/11/2001, gender, racial ethnic group, educational level at W1, smoking, marital status, and availability of social support at W2. Social support was defined as having both at least one close friend to speak to and having contact with friends or relatives at least twice a month. The effect of mode of enrollment into the Registry (self-identified or list-identified) and survey mode (mail, internet, or computer-assisted telephone interview [CATI]) at W2 were also measured. Exposure variables included intensity of envelopment by the dust cloud [Brackbill et al., 2009], day of arrival at one of the WTC sites, duration of work at the site, 9/11-related injury (laceration, sprain, bone fracture, or concussion), and four disaster-related events: loss of a job, fear of being injured on 9/11, losing a friend or family member on $9 / 11$, or witnessing a traumatic event (specifically, an airplane hitting the WTC, collapse of a building, people fleeing the dust cloud, someone injured or killed, or someone falling or jumping from the WTC).

Outcome variables reflecting the severity of respiratory illness included the number of days each LRS symptom was experienced during the 30 days prior to $\mathrm{W} 2$ and whether the enrollees had sought physician care for LRS, had been diagnosed after $9 / 11$ with asthma, RADS, chronic bronchitis or other obstructive lung disease, or had used a physician prescribed inhaler in the 30 days before responding to W2. Because physician diagnosis of asthma is considered a more specific indicator of severe respiratory illness than LRS alone, asthmatics with LRS were analyzed as a subgroup. Among this subset of responders, outcome variables included the proportion seeking care for asthma symptoms and the proportion with asthma morbidity in the 12 months prior to W2.

Measures of the severity of psychological illness at W2, 5-6 years after 9/11 included (a) individual PCL score; (b) median PCL score by comorbidity status; (c) number of questions within each of the three DSM-IV symptom categories where the responder reported at least moderate symptoms; (d) presence of post-9/11 diagnosed depression or anxiety disorder; (e) summary score on the Kessler-6 test scale for non-specific psychological distress, grouped as 0-7, 8-12, and 13-24 (a score of 13 or higher predicts meeting DSM-IV criteria for an anxiety or mood disorder [Kessler et al., 2002]); (f) whether the responder had talked to a mental health professional in the past 12 months; and (g) whether the responder was prescribed medication for a mental health condition in the past 12 months.

Three standardized questions measured quality of life (QOL): number of days in the past 30 days that (a) physical health was not good, (b) mental health was not good, and (c) daily activities were limited because of these problems [Centers for Disease Control and Prevention, 2000]. These measures were dichotomized as $<14$ and $\geq 14$ not good days [Zahran et al., 2005]. Unmet healthcare need was also assessed by asking whether the responder needed but did not receive health care, including mental health care or counseling, during the last 12 months.

\section{Statistical Analysis}

Analyses used SAS statistical software, version 9.2 (SAS Institute, Inc., Cary, NC). Two-tailed tests were used in all analyses. In bivariate analyses, demographic variables significantly associated with comorbid LRS and PTSD versus LRS alone and PTSD alone were identified. The chisquare test was used to determine group differences on categorical variables, and a maximum $P$-value of 0.05 was chosen for statistical significance. Next, the relationship of exposure variables to comorbidity status versus LRS only or PTSD only was examined while adjusting for demographic variables shown to be significant in our data and in the WTC disaster literature. Then the additional effect of comorbid LRS and PTSD on various respiratory health, mental health, and quality of life outcomes compared to the effect of either LRS or PTSD alone was determined in multivariable logistic regression models, assessed by odds ratios with 95\% confidence intervals (CI), while adjusting for significant demographic and disaster exposure variables. Specifically, the extent to which co-occurring PTSD and LRS versus LRS alone heightened the reporting of respiratory health problems was determined for each of the respiratory health outcomes. In addition, among asthmatics, the frequency of days with LRS in the 30 days prior to W2 was compared between comorbid responders and those with LRS alone using a nonparametric test (Wilcoxon two-samples test) because the distribution of affected days was non-normal.

PTSD severity based on median PCL score was compared between comorbid responders and those with PTSD alone using the Wilcoxon two-samples test. For all 
other measures of the severity of psychological illness, the relative difference between comorbid and PTSD alone was assessed by odds ratios adjusted for demographic and exposure variables.

Finally, the relative effect of comorbidity on quality of life was assessed for comorbid responders compared separately to those with PTSD alone and with LRS alone in multivariable logistic regression models adjusting for demographic and exposure variables.

\section{RESULTS}

The criteria for LRS alone were met by 2,157 (15.0\%) of responders and for PTSD alone by $1,058(7.4 \%) ; 1,413$ (9.8\%) were comorbid for LRS and PTSD (Table I). Of the 3,570 with LRS, $39.6 \%$ were comorbid, and of the 2,471 with PTSD, $57.2 \%$ were comorbid. Given a prevalence of $24.8 \%$ for LRS and $17.2 \%$ for PTSD in this Registry responder population, the expected number of comorbid individuals would have been 613 if these conditions were independent, whereas 1,413 were observed, 2.3 times as many as expected. The odds ratio for comorbid LRS and PTSD was 6.0 (95\% CI: $5.5,6.6)$.

Most (81.7\%) of the 14,388 responders were men. The mean age on September 11, 2001, for responders in the sample was 40.6 years, range $18-64$ years. The most common racial ethnic group was non-Hispanic whites (78.0\%), followed by Hispanics (10.8\%) and non-Hispanic blacks $(6.6 \%)$. Nearly three quarters reported some college education, although only $41.3 \%$ completed college. Only $13.5 \%$ reported that they currently smoked cigarettes, and $77.5 \%$ said they were married or living with a partner at W2.

Compared with those with LRS only, comorbid responders were more likely to be female, have only a high school education, be a smoker, widowed, divorced, separated, or never married rather than married, and lack social support at W2 (Table I). Comorbid responders compared to those with PTSD only were more likely to be male, older (4564 years), not to have completed college, to currently smoke, and to be widowed, divorced, or separated rather than married at W2. The distribution of race/ethnicity was similar in those with PTSD alone and with both conditions, but differed significantly from the distribution among those with LRS alone, due primarily to the disproportionately high percent of Hispanics with comorbid LRS and PTSD compared to LRS alone (17.8\% vs. $11.0 \%)$.

Just over half of the responders (52.3\%) reported arriving at the WTC site by September 12, and slightly more than one quarter of responders $(26.1 \%)$ reported intense exposure to the dust cloud (Table II). When physical and emotional exposure variables were compared between comorbid responders and those with LRS alone or PTSD alone (adjusting for demographic variables), intense dust cloud, earlier arrival at the WTC site, longer duration of work at the site, experiencing injury, losing one's job after $9 / 11$, fearing personal injury, losing a friend or relative, and witnessing a traumatic event on $9 / 11$ were significantly associated with comorbidity (Table II).

When compared to responders with LRS alone, comorbid responders were not significantly more likely to have reported persistent cough, but they were more than twice as likely than those with LRS alone to have reported dyspnea (adjusted odds ratio [aOR] 2.4, 95\% CI: 1.9, 2.9) and 1.5 times as likely to have reported wheezing for at least 8 of the 30 days prior to $\mathrm{W} 2$ (aOR 1.5, 95\% CI: 1.3, 1.9) (Table III). Comorbid responders were significantly more likely to have ever reported seeking care from a physician for dyspnea, wheezing, or persistent cough. They were also significantly more likely to have reported being diagnosed after $9 / 11$ with chronic bronchitis or other obstructive lung disease, and to have reported using a physician prescribed inhaler during the 30 days prior to W2. However, reported history of post-9/11 diagnosed asthma was not significantly associated with comorbidity.

Among the 1,510 responders who reported a post-9/11 diagnosis of asthma, those comorbid with LRS and PTSD $(\mathrm{n}=440)$ were nearly three times more likely to report having experienced dyspnea (aOR 2.9, 95\% CI: 1.8, 4.6) and 1.5 times as likely to report wheezing on at least 8 of the 30 days prior to $\mathrm{W} 2$ (aOR $1.5,95 \% \mathrm{CI}: 1.1,2.2)$, and were more likely to have sought care for dyspnea (aOR 3.2, 95\% CI: $1.5,6.9$ ) or persistent cough (aOR 2.0, 95\% CI: 1.3, 3.1) than were responders with asthma and LRS but not PTSD $(\mathrm{n}=548)$ (Table III). Responders with all three conditions also reported significantly more days of symptoms than those without PTSD. Median days of dyspnea, wheezing, and cough were 25,19 , and 15 , respectively, in comorbid asthmatic responders compared to 15,10 , and 10 among those with asthma and LRS but not PTSD $(P<0.001$ for each comparison, Wilcoxon two-samples test).

Responders with PTSD who were comorbid for LRS consistently reported more intense PTSD and additional mental health problems than those with PTSD alone (Table IV). Regarding the 30 days prior to W2, responders with LRS and PTSD scored significantly higher on the PCL in all three PTSD criteria than responders with PTSD alone. They were twice as likely to report at least moderate upset in all five re-experiencing questions (aOR 2.1, 95\% CI: 1.6, 2.8 ). They were also significantly more likely to report at least moderate difficulty in six or more of the avoidance questions (aOR 1.4, 95\% CI: 1.1, 1.8) and in all five arousal items (aOR $1.6,95 \%$ CI: 1.3, 1.9). Comorbid responders were more likely to score significantly higher on the Kessler-6 scale for nonspecific psychological distress during the 30 days prior to $\mathrm{W} 2$ (median 13 vs. $11, P<0.001$ by Wilcoxon two-samples test), and to score in the upper distress range of 13 or higher versus $0-7$ (aOR 2.5, 95\% CI: 1.8, 3.3). Responders with PTSD and LRS were significantly were more likely to report 
TABLE I. Associations Between Comorbid Lower Respiratory Symptoms and Posttraumatic Stress Disorder and Demographic Factors

\begin{tabular}{|c|c|c|c|c|c|c|c|c|c|c|c|}
\hline & Total & $\begin{array}{l}\text { Neither } \\
\text { condition }\end{array}$ & $\%$ & $\begin{array}{l}\text { LRS } \\
\text { only }\end{array}$ & $\%$ & $\begin{array}{l}\text { PTSD } \\
\text { only }\end{array}$ & $\%$ & $\begin{array}{l}\text { Both LRS } \\
\text { and PTSD }\end{array}$ & $\%$ & $\begin{array}{c}\text { LRS } \\
\text { and } \\
\text { PTSD vs. } \\
\text { LRS alone }^{\text {a,b }}\end{array}$ & $\begin{array}{c}\text { LRS } \\
\text { and } \\
\text { PTSD vs. } \\
\text { PTSD } \\
\text { alone }^{\text {a,b }}\end{array}$ \\
\hline All responders & 14,388 & 9,760 & 67.8 & 2,157 & 15.0 & 1,058 & 7.4 & 1,413 & 9.8 & & \\
\hline Sex & & & & & & & & & & 0.031 & 0.001 \\
\hline Female & 2,638 & 1,985 & 20.3 & 252 & 11.7 & 201 & 19.0 & 200 & 14.2 & & \\
\hline Male & 11,750 & 7,775 & 79.7 & 1,905 & 88.3 & 857 & 81.0 & 1,213 & 85.8 & & \\
\hline Age (in years) on 9/11/2001 & & & & & & & & & & n.s. ${ }^{\mathrm{c}}$ & 0.012 \\
\hline $18-24$ & 620 & 476 & 4.9 & 57 & 2.6 & 50 & 4.7 & 37 & 2.6 & & \\
\hline $25-44$ & 8,910 & 5,927 & 60.7 & 1,378 & 63.9 & 690 & 65.2 & 915 & 64.8 & & \\
\hline $45-64$ & 4,858 & 3,357 & 34.4 & 722 & 33.5 & 318 & 30.1 & 461 & 32.6 & & \\
\hline Race Ethnicity & & & & & & & & & & $<0.001$ & n.s. \\
\hline Asian & 302 & 212 & 2.2 & 36 & 1.7 & 26 & 2.5 & 28 & 2.0 & & \\
\hline Hispanic & 1,551 & 893 & 9.2 & 238 & 11.0 & 168 & 15.9 & 252 & 17.8 & & \\
\hline Non-Hispanic Black & 951 & 647 & 6.6 & 115 & 5.3 & 95 & 9.0 & 94 & 6.7 & & \\
\hline Other & 358 & 198 & 2.0 & 60 & 2.8 & 51 & 4.8 & 49 & 3.5 & & \\
\hline Non-Hispanic White & 11,226 & 7,810 & 80.0 & 1,708 & 79.2 & 718 & 67.9 & 990 & 70.1 & & \\
\hline Education & & & & & & & & & & $<0.001$ & $<0.001$ \\
\hline High school or less & 3,831 & 2,336 & 24.0 & 652 & 30.4 & 314 & 29.9 & 529 & 37.7 & & \\
\hline Some college & 4,578 & 2,924 & 30.0 & 823 & 38.3 & 349 & 33.2 & 482 & 34.3 & & \\
\hline College/post-graduate & 5,927 & 4,473 & 46.0 & 673 & 31.3 & 388 & 36.9 & 393 & 28.0 & & \\
\hline Smoking history & & & & & & & & & & $<0.001$ & $<0.001$ \\
\hline Current smoker & 1,942 & 986 & 10.1 & 385 & 17.9 & 201 & 19.0 & 370 & 26.3 & & \\
\hline Past smoker or never smoked & 12,409 & 8,752 & 89.9 & 1,767 & 82.1 & 855 & 81.0 & 1,035 & 73.7 & & \\
\hline Marital status & & & & & & & & & & $<0.001$ & 0.025 \\
\hline Widowed/divorced/separated & 1,632 & 931 & 9.6 & 270 & 12.6 & 160 & 15.2 & 271 & 19.4 & & \\
\hline Never married & 1,579 & 1,101 & 11.4 & 182 & 8.5 & 133 & 12.6 & 163 & 11.7 & & \\
\hline Married/living with partner & 11,062 & 7,650 & 79.0 & 1,688 & 78.9 & 760 & 72.2 & 964 & 69.0 & & \\
\hline Social support & & & & & & & & & & $<0.001$ & n.s. \\
\hline $\begin{array}{l}\text { Both a close friend and contact } \\
\text { with friends } \geq \text { twice/month }\end{array}$ & 7,940 & 5,991 & 62.3 & 1,146 & 54.0 & 364 & 34.8 & 439 & 31.4 & & \\
\hline Lacking either or both & 6,251 & 3,632 & 37.7 & 976 & 46.0 & 683 & 65.2 & 960 & 68.6 & & \\
\hline Mode of recruitment Wave 1 & & & & & & & & & & n.s. & n.s. \\
\hline Self-identified & 9,969 & 6,390 & 65.5 & 1,681 & 77.9 & 804 & 76.0 & 1,094 & 77.4 & & \\
\hline List-identified & 4,419 & 3,370 & 34.5 & 476 & 22.1 & 254 & 24.0 & 319 & 22.6 & & \\
\hline Survey mode at Wave 2 & & & & & & & & & & 0.002 & 0.012 \\
\hline Mail & 7,016 & 4,659 & 47.7 & 1,081 & 50.1 & 510 & 48.2 & 766 & 54.2 & & \\
\hline Web & 5,850 & 3,983 & 40.8 & 857 & 39.7 & 461 & 43.6 & 549 & 38.9 & & \\
\hline CATI & 1,522 & 1,118 & 11.5 & 219 & 10.2 & 87 & 8.2 & 98 & 6.9 & & \\
\hline
\end{tabular}

LRS, lower respiratory symptoms; PTSD, posttraumatic stress disorder.

${ }^{\text {a }}$ Chi-square $P$-value.

${ }^{\mathrm{b}}$ Statistically significant results are bolded.

${ }^{c}$ n.s. if $P \geq 0.05$.

being diagnosed post-9/11 with PTSD and depression than responders with PTSD alone. Finally, in the 12 months prior to W2, responders with both LRS and PTSD reported talking to a mental health professional significantly more often than responders with PTSD alone (aOR 1.4, 95\% CI: 1.1, 1.7).
Nearly two-thirds $(65.1 \%)$ of comorbid responders reported less than good general health (Table V) compared with only $32.1 \%$ for those with only LRS and $34.1 \%$ for those with only PTSD (aORs $2.7,95 \%$ CI: $2.3,3.3$, and 3.7, 95\% CI: $3.0,4.7$, respectively). Over half $(53.2 \%)$ of comorbid 
TABLE II. Adjusted Odds Ratios for Associations Between Exposure Variables and Comorbid Outcomes

\begin{tabular}{|c|c|c|c|c|c|c|c|c|c|c|c|}
\hline Factor & Total & $\begin{array}{l}\text { Neither } \\
\text { condition }\end{array}$ & $\%$ & $\begin{array}{l}\text { LRS } \\
\text { only }\end{array}$ & $\%$ & $\begin{array}{l}\text { PTSD } \\
\text { only }\end{array}$ & $\%$ & $\begin{array}{l}\text { Both LRS } \\
\text { and PTSD }\end{array}$ & $\%$ & $\begin{array}{c}\text { aOR LRS } \\
\text { and } \\
\text { PTSD vs. LRS }{ }^{a, c}\end{array}$ & $\begin{array}{c}\text { aOR, LRS } \\
\text { and } \\
\text { PTSD vs. PTSD } \\
\text { P,c }\end{array}$ \\
\hline \multicolumn{12}{|l|}{ Dust cloud exposure } \\
\hline None & 7,473 & 5,816 & 67.4 & 859 & 47.4 & 403 & 46.1 & 395 & 33.4 & Ref & Ref \\
\hline Some & 1,768 & 1,148 & 13.3 & 318 & 17.5 & 146 & 16.7 & 156 & 13.2 & $1.2(0.9,1.5)$ & $1.2(0.9,1.5)$ \\
\hline Intense & 3,264 & 1,670 & 19.3 & 636 & 35.1 & 326 & 37.3 & 632 & 53.4 & $2.4(2.0,2.9)$ & $2.2(1.8,2.7)$ \\
\hline \multicolumn{12}{|l|}{ Arrival at WTC } \\
\hline $9 / 18 / 01-6 / 30 / 02$ & 3,785 & 3,061 & 32.6 & 328 & 15.6 & 189 & 18.2 & 207 & 14.8 & Ref & Ref \\
\hline $9 / 13-9 / 17$ & 2,862 & 2,001 & 21.3 & 378 & 18.0 & 250 & 24.1 & 233 & 16.7 & $1.1(0.8,1.4)$ & $0.9(0.7,1.2)$ \\
\hline $9 / 12$ & 2,867 & 1,812 & 19.3 & 507 & 24.1 & 237 & 22.8 & 311 & 22.3 & $1.0(0.8,1.3)$ & $1.2(0.9,1.5)$ \\
\hline $9 / 11$ & 4,407 & 2,510 & 26.8 & 889 & 42.3 & 363 & 34.9 & 645 & 46.2 & $1.4(1.1,1.8)$ & $1.7(1.3,2.2)$ \\
\hline \multicolumn{12}{|l|}{ Duration of work at WTC } \\
\hline $1-7$ days & 3,386 & 2,541 & 29.9 & 359 & 18.9 & 235 & 25.8 & 251 & 19.7 & Ref & Ref \\
\hline $8-30$ days & 2,488 & 1,813 & 21.4 & 348 & 18.3 & 144 & 15.8 & 183 & 14.3 & $0.8(0.6,1.0)$ & $1.2(0.9,1.6)$ \\
\hline $31-90$ days & 2,056 & 1,343 & 15.8 & 329 & 17.3 & 177 & 19.4 & 207 & 16.2 & $0.98(0.8,1.3)$ & $1.1(0.8,1.4)$ \\
\hline$>90$ days & 4,646 & 2,790 & 32.9 & 866 & 45.5 & 355 & 39.0 & 635 & 49.8 & $1.2(0.94,1.4)$ & $1.7(1.3,2.1)$ \\
\hline \multicolumn{12}{|l|}{ Any injury on 9/11 } \\
\hline No & 12,074 & 8,670 & 89.1 & 1,683 & 78.3 & 815 & 77.5 & 906 & 64.3 & Ref & Ref \\
\hline Yes & 2,267 & 1,061 & 10.9 & 467 & 21.7 & 237 & 22.5 & 502 & 35.7 & $2.2(1.9,2.6)$ & $1.9(1.6,2.3)$ \\
\hline \multicolumn{12}{|l|}{ Lost job after $9 / 11$} \\
\hline No & 12,543 & 8,941 & 92.5 & 1,900 & 88.9 & 790 & 75.4 & 912 & 65.7 & Ref & Ref \\
\hline Yes, but not due to $9 / 11$ & 945 & 512 & 5.3 & 126 & 5.9 & 126 & 12.0 & 181 & 13.0 & $2.7(2.1,3.4)$ & $1.2(0.94,1.6)$ \\
\hline Yes, due to $9 / 11$ & 754 & 215 & 2.2 & 112 & 5.2 & 132 & 12.6 & 295 & 21.3 & $4.7(3.7,6.0)$ & $1.9(1.5,2.4)$ \\
\hline \multicolumn{12}{|l|}{$\begin{array}{l}\text { Thought might be injured } \\
\text { or killed on } 9 / 11\end{array}$} \\
\hline No & 8,569 & 6,579 & 68.4 & 1,138 & 53.9 & 408 & 39.2 & 444 & 32.2 & Ref & Ref \\
\hline Yes & 5,590 & 3,045 & 31.6 & 974 & 46.1 & 634 & 60.8 & 937 & 67.8 & $2.6(2.3,3.1)$ & $1.4(1.2,1.6)$ \\
\hline \multicolumn{12}{|l|}{$\begin{array}{l}\text { Know someone who } \\
\text { died on } 9 / 11\end{array}$} \\
\hline No & 5,455 & 4,298 & 44.5 & 578 & 27.1 & 302 & 29.0 & 277 & 19.9 & Ref & Ref \\
\hline Yes & 8,776 & 5,371 & 55.5 & 1,552 & 72.9 & 740 & 71.0 & 1,113 & 80.1 & $1.8(1.5,2.2)$ & $1.7(1.4,2.1)$ \\
\hline \multicolumn{12}{|l|}{$\begin{array}{l}\text { Witnessing a traumatic } \\
\text { event on } 9 / 11\end{array}$} \\
\hline No & 7,079 & 5,444 & 55.8 & 865 & 40.1 & 396 & 37.5 & 374 & 26.5 & Ref & Ref \\
\hline Yes & 7,294 & 4,304 & 44.2 & 1,290 & 59.9 & 661 & 62.5 & 1,039 & 73.5 & $2.0(1.7,2.3)$ & $1.7(1.5,2.1)$ \\
\hline
\end{tabular}

LRS, lower respiratory symptoms; PTSD, posttraumatic stress disorder; aOR, adjusted odds ratio.

${ }^{a}$ Comorbid LRS and PTSD versus LRS alone, adjusting for age, race/ethnicity, sex, education, marital status, current smoking, social support, recruitmentmethod, and survey mode.

${ }^{\mathrm{b}}$ Comorbid LRS and PTSD versus PTSDS alone, adjusting for age, race/ethnicity, sex, education, marital status, current smoking, social support, recruitment method, and survey mode.

${ }^{\mathrm{c}}$ Statistically significant results are bolded.

responders reported experiencing poor physical health for at least 14 of the 30 days before W2; they were twice as likely to so report than were responders with LRS but not PTSD. Comorbid responders were also significantly more likely to report having at least 14 days of poor mental health than responders with PTSD but not LRS (aOR 1.7, 95\% CI: 1.4, $2.1)$. Nearly half $(48.4 \%)$ of comorbid responders reported that poor health kept them from doing their usual activities for at least 14 of the last 30 days before W2. Comorbid responders were considerably more likely than those with LRS alone or PTSD alone to report $\geq 14$ days lost to poor health (aORs 4.0, 95\% CI: 3.3, 5.0, and 2.3, 95\% CI: 1.8, 2.9, respectively).

Comorbid responders were more likely than those with either LRS or PTSD alone to report not getting health care that they needed during the 12 months prior toW2 (aORs 2.1, 95\% CI: $1.7,2.5$, and 1.8, 95\% CI: 1.5, 2.3, respectively). 
TABLE III. Comorbid LRS and PTSD and Respiratory Symptoms and Conditions

\begin{tabular}{|c|c|c|c|c|c|c|}
\hline & & & & & & \\
\hline & Total & No. & $\overline{\%}$ & No. & $\%$ & vs. $\operatorname{LRS}_{\mathrm{aO}} \mathrm{R}^{\mathrm{a}, \mathrm{b}}$ \\
\hline All Workers & 14,388 & 2,157 & 15.0 & 1,413 & 9.8 & \\
\hline $\begin{array}{l}\text { Experienced } \geq 8 \text { days } \\
\text { of symptom in last } 30 \text { days }\end{array}$ & & & & & & \\
\hline Dyspnea & 2,233 & 1,153 & 54.5 & 1,080 & 78.1 & $2.4(1.9,2.9)$ \\
\hline Wheezing & 1,588 & 853 & 40.4 & 735 & 54.3 & $1.5(1.3,1.9)$ \\
\hline Persistent cough & 2,044 & 1,230 & 58.0 & 814 & 58.7 & $0.94(0.8,1.1)$ \\
\hline Ever sought care for & & & & & & \\
\hline Dyspnea & 4,593 & 1,403 & 65.7 & 1,152 & 82.8 & $2.0(1.6,2.5)$ \\
\hline Wheezing & 3,631 & 1,171 & 55.3 & 962 & 70.4 & $1.6(1.3,1.9)$ \\
\hline Persistent cough & 4,209 & 1,118 & 52.0 & 859 & 61.1 & $1.3(1.1,1.6)$ \\
\hline Chronic conditions $^{\mathrm{C}}$ & & & & & & \\
\hline Asthma & 1,510 & 548 & 25.4 & 440 & 31.1 & $1.1(0.93,1.4)$ \\
\hline Chronic bronchitis & 1,145 & 359 & 16.9 & 390 & 28.0 & $1.7(1.4,2.2)$ \\
\hline Any obstructive disease $^{d}$ & 2,274 & 758 & 35.2 & 638 & 45.2 & $1.3(1.1,1.6)$ \\
\hline Inhaler use in last 30 days & 1,805 & 660 & 30.8 & 583 & 41.7 & $1.3(1.1,1.6)$ \\
\hline Workers with diagnosed asthma & & & & & & \\
\hline $\begin{array}{l}\text { Experienced } \geq 8 \text { days } \\
\text { of symptom in last } 30 \text { days }\end{array}$ & & & & & & \\
\hline Dyspnea & 767 & 384 & 71.6 & 383 & 88.5 & $2.9(1.8,4.6)$ \\
\hline Wheezing & 646 & 339 & 63.4 & 307 & 73.1 & $1.5(1.1,2.2)$ \\
\hline Persistent cough & 530 & 262 & 48.7 & 268 & 61.5 & $1.3(0.90,1.8)$ \\
\hline Ever sought care for & & & & & & \\
\hline Dyspnea & 1,286 & 492 & 90.1 & 417 & 95.2 & $3.2(1.5,6.9)$ \\
\hline Wheezing & 1,218 & 483 & 89.4 & 387 & 89.8 & $1.5(0.8,2.5)$ \\
\hline Persistent cough & 1,023 & 376 & 69.1 & 362 & 82.8 & $2.0(1.3,3.1)$ \\
\hline Asthma events in past 12 mon & & & & & & \\
\hline Asthma attack & 1,010 & 393 & 73.7 & 354 & 83.3 & $1.3(0.8,1.9)$ \\
\hline Inhaler use & 1,103 & 433 & 81.4 & 373 & 88.0 & $1.1(0.7,1.8)$ \\
\hline ER visit for asthma & 306 & 115 & 21.6 & 129 & 30.2 & $1.4(0.95,2.2)$ \\
\hline
\end{tabular}

LRS, lower respiratory symptoms; PTSD, posttraumatic stress disorder; aOR, adjusted odds ratio.

aComorbid LRS and PTSD versus LRS alone, adjusting for age group at 9/11, sex, race/ethnicity, education level, marital status, social support, smoking, recruitmentmethod, surveymode,dustcloud intensity, earliestworkperiod,duration of work,loss ofjobdueto $9 / 11$,fear of beinginjured, experiencing injury,loss of afriend or relative, and witnessing trauma on $9 / 11$.

${ }^{\mathrm{b}}$ Statistically significant results bolded.

${ }^{\mathrm{C}}$ First diagnosed after $9 / 11$.

${ }^{\mathrm{d}}$ Asthma, chronic bronchitis, COPD, emphysema.

However, there were no significant differences between comorbid responders and those with PTSD alone in expressing an unmet need for mental health counseling.

\section{DISCUSSION}

Co-occurring LRS and PTSD in this study was significantly associated with severity of respiratory and mental illnesses, disability, and poor quality of life. These associations held while controlling for WTC exposures that have been shown in previous studies to be correlated with comorbidity, including dust cloud intensity, date of arrival at the WTC site, duration of work, personal injury, and emotional trauma.

These findings of significant respiratory and mental illness comorbidity are consistent with recent studies of firefighters and other rescue and recovery workers [Niles et al., 2011; Luft et al., 2012]. Niles et al. [2011] found a moderate association between WTC cough syndrome and probable PTSD among exposed NYC firefighters. The causal path models developed by Luft et al. [2012] suggest that, among police as well other responders, associations between exposures and respiratory outcomes were mediated in part by 
TABLE IV. Comorbid LRS and PTSD and Mental Health Symptoms and Conditions

\begin{tabular}{|c|c|c|c|c|c|c|}
\hline & \multirow[b]{2}{*}{ Total number } & \multicolumn{2}{|c|}{ PTSD } & \multicolumn{2}{|c|}{ LRS and PTSD } & \multirow{2}{*}{$\begin{array}{l}\text { LRS and PTSD } \\
\text { vs. PTSD } a \text { OR }^{\mathrm{a}, \mathrm{b}}\end{array}$} \\
\hline & & Number & $\%$ & Number & $\%$ & \\
\hline & 14,388 & 1,058 & 7.4 & 1,413 & 9.8 & \\
\hline PTSD symptoms in last 30 days & & & & & & $\boldsymbol{P}<0.001^{c}$ \\
\hline Median PCL score $(Q 1, Q 3)$ & & \multicolumn{2}{|c|}{$53(48,60)$} & \multicolumn{2}{|c|}{$59(52,67)$} & \\
\hline \multicolumn{7}{|l|}{ DSM IV criteria reexperiencing symptoms } \\
\hline 5 & 942 & 290 & 27.4 & 594 & 42.0 & $2.1(1.6,2.8)$ \\
\hline $3-4$ & 1,475 & 420 & 39.7 & 524 & 37.1 & $1.5(1.1,1.9)$ \\
\hline $1-2$ & 3,358 & 348 & 32.9 & 295 & 20.9 & Ref \\
\hline 0 & 8,613 & 0 & 0.0 & 0 & 0.0 & \\
\hline \multicolumn{7}{|l|}{ Avoidance symptoms } \\
\hline $6-7$ & 1,261 & 460 & 43.5 & 759 & 53.7 & $1.4(1.1,1.8)$ \\
\hline 5 & 617 & 227 & 21.5 & 263 & 18.6 & $1.1(0.8,1.5)$ \\
\hline $3-4$ & 1,667 & 371 & 35.1 & 391 & 27.7 & Ref \\
\hline $0-2$ & 10,843 & 0 & 0.0 & 0 & 0.0 & \\
\hline \multicolumn{7}{|l|}{ Arousal symptoms } \\
\hline 5 & 1,645 & 520 & 49.1 & 888 & 62.8 & $1.6(1.3,1.9)$ \\
\hline $2-4$ & 3,662 & 538 & 50.9 & 525 & 37.2 & $\operatorname{Ref}(0-4)$ \\
\hline $0-1$ & 9,081 & 0 & 0.0 & 0 & 0.0 & \\
\hline Non-specific psychological distress in last 30 days & 14,247 & 1,049 & 7.4 & 1,397 & 9.8 & \\
\hline $13-24$ & 1,346 & 365 & 34.8 & 754 & 54.0 & $2.5(1.8,3.3)$ \\
\hline $8-12$ & 2,176 & 447 & 42.6 & 464 & 33.2 & $1.3(0.95,1.7)$ \\
\hline $0-7$ & 10,725 & 237 & 22.6 & 179 & 12.8 & Ref \\
\hline \multicolumn{7}{|l|}{ Mental health diagnoses post-9/11 } \\
\hline PTSD & 1,752 & 347 & 33.3 & 673 & 48.8 & $1.5(1.2,1.9)$ \\
\hline Depression & 2,123 & 420 & 41.1 & 767 & 56.0 & $1.6(1.3,1.9)$ \\
\hline Anxiety & 1,279 & 254 & 24.5 & 454 & 33.0 & $1.2(0.95,1.5)$ \\
\hline Talked to a mental health professional in last 12 months & 2,478 & 368 & 34.8 & 636 & 45.2 & $1.4(1.1,1.7)$ \\
\hline Taken medication prescribed for mental or emotional problem & 1,409 & 244 & 23.1 & 449 & 32.0 & $1.3(0.99,1.6)$ \\
\hline
\end{tabular}

LRS, lower respiratory symptoms; PTSD, posttraumatic stress disorder; aOR, adjusted odds ratio.

${ }^{a}$ Comorbid LRSand PTSDversusPTSDalone, adjusting forage,gender,race/ethnicity,education, maritalstatus, socialsupport,smoking, method of recruitment,surveymode, intense dust cloud exposure, earliest work period, duration worked at WTC, job loss due to $9 / 11$, fear of being injured or killed, loss of friend or relative, personal injury, and witnessing trauma on $9 / 11$.

${ }^{\mathrm{b}}$ Statistically significant values are bolded.

'Wilcoxon two-samples test.

PTSD. The current study confirms the associations previously found in responders as well as in survivors [Nair et al., 2012], and documents the intensifying effect of comorbidity on the reporting of respiratory and psychological problems, increased disability, and decreased quality of life.

Numerous risk factors for both LRS and PTSD were documented in this study. Comorbid responders were more likely to be smokers and less likely to be married or living with a partner; they had less education and less social support. They were more likely on $9 / 11$ to have had physical exposures such as being in the dust cloud or bodily injury, and emotional trauma such as losing a job, losing a friend or relative, or personally witnessing traumatic events. However, even when these differences in demographics and exposures were controlled for, comorbidity with PTSD was associated with intensified respiratory symptoms in responders reporting LRS, and comorbidity with LRS was linked to increased reporting of the re-experiencing, avoidance, and arousal components in responders with PTSD. Comorbid responders were also more likely to report having other psychological problems and to report receiving mental health treatment in the 12 months prior to W2. The health burden of comorbid LRS and PTSD was also reflected in greater reporting of poor physical, mental, and overall health.

A strength of Registry studies is the presence of large worker and survivor populations, which permits detailed analysis of subgroups. Compared with results previously reported in survivors [Nair et al., 2012], in the current study, responders were only slightly more likely to report PTSD $(17.2 \%$ vs. $14.3 \%)$, but were considerably more likely to 
TABLE V. Comorbidity, Quality of Life, and Unmet Healthcare Needs

\begin{tabular}{|c|c|c|c|c|c|c|c|c|c|c|c|}
\hline All responders & Total & Neither & $\%$ & $\begin{array}{l}\text { LRS } \\
\text { only }\end{array}$ & $\%$ & $\begin{array}{l}\text { PTSD } \\
\text { only }\end{array}$ & $\%$ & $\begin{array}{c}\text { LRS } \\
\text { and PTSD }\end{array}$ & $\%$ & & \\
\hline & 14,388 & 9,760 & 67.8 & 2,157 & 15.0 & 1,058 & 7.4 & 1,413 & 9.8 & & \\
\hline $\begin{array}{l}\text { Responders } \\
\text { answering yes to: }\end{array}$ & Total & Neither & $\%^{a}$ & $\begin{array}{l}\text { LRS } \\
\text { only }\end{array}$ & $\%^{a}$ & $\begin{array}{l}\text { PTSD } \\
\text { only }\end{array}$ & $\%^{\mathrm{a}}$ & $\begin{array}{l}\text { LRS and } \\
\text { PTSD }\end{array}$ & $\%^{a}$ & $\begin{array}{l}\text { aORs }^{\text {b,d }} \text { LRS } \\
\text { and PTSD } \\
\text { vs. LRS }\end{array}$ & $\begin{array}{c}\text { aORs }^{\mathrm{c}, \mathrm{d}} \text { LRS and } \\
\text { PTSD } \\
\text { vs. PTSD }\end{array}$ \\
\hline $\begin{array}{l}\text { Fair or poor } \\
\text { general health }\end{array}$ & 2,707 & 753 & 7.8 & 687 & 32.1 & 357 & 34.1 & 910 & 65.1 & $2.7(2.3,3.3)$ & $3.7(3.0,4.7)$ \\
\hline $\begin{array}{l}\text { Poor physical } \\
\quad \text { health } \geq 14 \text { days }\end{array}$ & 2,430 & 829 & 8.6 & 618 & 28.9 & 243 & 23.3 & 740 & 53.2 & $2.0(1.7,2.4)$ & $3.6(2.8,4.5)$ \\
\hline $\begin{array}{l}\text { Poor mental } \\
\quad \text { health } \geq 14 \text { days }\end{array}$ & 2,493 & 707 & 7.3 & 378 & 17.8 & 488 & 46.8 & 920 & 65.9 & $6.6(5.4,8.1)$ & $1.7(1.4,2.1)$ \\
\hline $\begin{array}{l}\text { Days lost to poor } \\
\quad \text { health } \geq 14\end{array}$ & 1,664 & 423 & 4.6 & 307 & 14.7 & 262 & 25.3 & 672 & 48.4 & $4.0(3.3,5.0)$ & $2.3(1.8,2.9)$ \\
\hline $\begin{array}{l}\text { Did not get } \\
\quad \text { needed health care }\end{array}$ & 2,748 & 1,254 & 12.9 & 522 & 24.4 & 349 & 33.2 & 623 & 44.6 & $2.1(1.7,2.5)$ & $1.8(1.5,2.3)$ \\
\hline $\begin{array}{l}\text { Did not get } \\
\text { needed mental } \\
\text { health counseling }\end{array}$ & 748 & 162 & 14.2 & 78 & 16.0 & 186 & 55.4 & 322 & 53.6 & $6.0(4.0,8.8)$ & $0.95(0.7,1.4)$ \\
\hline
\end{tabular}

LRS, lower respiratory symptoms; PTSD, posttraumatic stress disorder; a0Rs, adjusted odds ratios.

${ }^{a}$ Percentage of responders answering yes of those answering the question.

${ }^{\mathrm{b}}$ Quality of life indicators in comorbid responders versus responders with LRS alone, adjusting for age group at $9 / 11$, sex, race/ethnicity, education level, marital status, social support,smoking,recruitmentmethod, surveymode,dustcloudintensity, earliestworkperiod,durationworkedatWTC,joblossdueto $9 / 11$, fear ofbeing injured or killed,loss ofa friend or relative, personal injury, and witnessing trauma on 9/11.

${ }^{c}$ Quality of life indicators in comorbidresponders versus responders with PTSDalone, adjusting for age group at $9 / 11$, sex,race/ethnicity, educationlevel, marital status, social support,smoking,recruitmentmethod, surveymode,dustcloudintensity, earliestworkperiod,durationworkedatWTC,joblossdueto $9 / 11$, fear ofbeing injured orkilled,loss of a friend or relative, personal injury, and witnessing trauma on 9/11.

${ }^{\mathrm{d}}$ Statistically significant values are bolded.

${ }^{\mathrm{e}}$ Among those who had an unmet healthcare need.

report LRS ( $24.8 \%$ vs. $14.9 \%)$. Hence, it is not unexpected that responders and survivors with LRS were comorbid with PTSD in similar proportions $(39.6 \%$ vs. $38.7 \%)$, while responders with PTSD were comorbid with LRS in greater proportions than were survivors (57.2\% vs. $40.4 \%)$.

Factors associated with increased reporting of comorbid LRS and PTSD among responders were strikingly similar among survivors in the Registry [Nair et al., 2012]. Educational level, pre-9/11 diagnosed depression, and lack of social support had similar associations with comorbidity for responders and survivors. Intense exposure to the dust cloud on 9/11 was also associated with comorbidity among both groups. Work exposure measures such as earlier arrival and longer duration of working at the site increased the likelihood of comorbid illness among responders, just as exposure to dust in the workplace or home increased the likelihood of comorbidity in survivors.

The association between comorbidity and intensity of poor respiratory health outcomes noted among survivors by Nair et al. [2012] was even stronger among responders for some exposure and outcome variables. Adjusted odds ratios for responders for seeking care for persistent cough, for reported post-9/11 diagnosis of chronic bronchitis or other obstructive disease, and for inhaler use in the past 30 days were significantly associated with comorbidity among responders but not among survivors. However, the increased reporting of respiratory health problems and increased days lost to poor health among comorbid asthmatic responders were similar to reporting in comorbid asthmatic survivors.

The association between comorbidity and a higher rate of reporting of adverse mental health outcomes including nonspecific psychological distress and diagnosed PTSD and depression, previously reported in survivors, was also noted in responders. The association between talking to a mental health professional and comorbidity appeared to be stronger in responders. It may also be that access to sources of mental health care was more of an issue for survivors, since comorbidity was associated with inability to get needed mental health services among survivors [Nair et al., 2012] but not among responders. 
The net effect of comorbid LRS and PTSD was reflected in greater reporting of poor physical, mental, and overall health. More than $40 \%$ of both responders and survivors who were comorbid for LRS and PTSD experienced significant disability based on reporting greater than 14 days' activity lost to poor health during the 30 days prior to W2 [Nair et al., 2012]. These data clearly demonstrate the continuing heavy burden of comorbid LRS and PTSD across WTC disaster affected groups.

Evidence for concurrence of respiratory symptoms or asthma and psychological illnesses has been presented in veterans and other populations [Wright et al., 1998; Goodwin et al., 2007; O'Toole and Catts, 2008], although the biological mechanisms are not well understood. WTC disaster exposures and experiences provided stimuli to initiate physical and mental illnesses. PTSD may have increased LRS through a compromising effect on the immune response [Boscarino, 2004] or through enhanced perception. LRS, as an ongoing reminder of the physical health effects of the disaster, may have stimulated PTSD symptoms. Together they resulted in a higher reported prevalence and intensification of both illnesses.

A potential limitation of this study is the high proportion of self-identified (69\%) compared to list-identified (31\%) participants, which raises a concern regarding possible selection bias. However, source of recruitment was not significantly associated with comorbidity. Another limitation is that symptoms and diagnoses were self-reported, with potential for reporting bias. As Nair et al. [2012] pointed out in their study of comorbidity in the survivor population, the Registry lacks objective measures of scope and severity of respiratory symptoms. Nevertheless, in a study of survivors nested within this Registry cohort, Friedman et al. [2011] found a significant association between reported LRS and lower airway dysfunction measured by pulmonary function testing (spirometry and impulse oscillometry). Furthermore, many of the Registry questionnaire-derived physical and mental health outcomes have been consistently found to be associated with a wide variety of 9/11 exposure measures in responder as well as survivor populations [Perrin et al., 2007; Wheeler et al., 2007; Brackbill et al., 2009; Li et al., 2011; Maslow et al., 2012], and the psychological measures used in the current study (PCL and Kessler-6) are well validated.

Because physician diagnosis of respiratory conditions like asthma may be affected by access to care, responders' report of LRS was used as the primary qualification for respiratory illness. Reported physician diagnosis of respiratory disease in subanalyses supplemented and supported associations found in responders with LRS but lacking a respiratory diagnosis.

This study demonstrated the compounding effect of comorbidity on the severity of LRS and PTSD, and on the attendant increased disability and diminished quality of life. These effects remained significant even while controlling for factors noted to affect physical and mental health outcomes. The results are consistent with and expand on those found in prior research on responders and survivors. Taken together, these studies indicate the necessity of examining responders and survivors for both respiratory and mental health illness when either is suspected, coordinating treatment when both are diagnosed, and assuring that mental health needs are fully met. Disaster planning efforts must include preparation for coordinated multidisciplinary clinical activities.

\section{ACKNOWLEDGMENTS}

This publication was supported by Cooperative Agreement Numbers 2U50OH009739 and 1U50OH009739 from CDCNIOSH, and U50/ATU272750 from CDC-ATSDR, which included support from CDC-NCEH, and the New York City Department of Health and Mental Hygiene (NYC DOHMH). Its contents are solely the responsibility of the authors and do not necessarily represent the official views of CDC.

\section{REFERENCES}

American Psychiatric Association. 2000. Diagnostic and Statistical Manual of Mental Disorders, 4th revised edition. Washington, DC: American Psychiatric Association.

Banauch GI, Hall C, Weiden M, Cohen HW, Aldrich TK, Christodoulou V, Arcentales N, Kelly KJ, Prezant DJ. 2006. Pulmonary function after exposure to the World Trade Center collapse in the New York City Fire Department. Am J Respir Crit Care Med 174:312-319.

Berninger A, Webber MP, Cohen HW, Gustave J, Lee R, Niles JK, Chiu S, Zeig-Owens R, Soo J, Kelly K, Prezant DJ. 2010. Trends of elevated PTSD in firefighters exposed to the World Trade Center disaster: 20012005. Public Health Rep 125:556-566.

Blanchard EB, Jones-Alexander J, Buckley TC, Forneris CA. 1996. Psychometric properties of the PTSD Checklist (PCL). Behav Res Ther 34(8):669-673.

Blechert J, Michael T, Grossman P, Lajtman M. 2007. Autonomic and respiratory characteristics of posttraumatic stress disorder and panic disorder. Psychosom Med 69:935-943.

Boscarino JA. 2004. Posttraumatic stress disorder and physical illness, results from clinical and epidemiologic studies. Ann NY Acad Sci 1032:141-153.

Brackbill RM, Hadler JL, DiGrande L, Ekenga CC, Farfel MR, Friedman S, Perlman SE, Stellman SD, Walker DJ, Wu D, Yu S, Thorpe LE. 2009. Asthma and posttraumatic stress symptoms 5 to 6 years following exposure to the World Trade Center Terrorist Attack. JAMA 302:502-516.

Centers for Disease Control and Prevention. 2000. Measuring healthy days. Atlanta, GA: CDC.

Cukor J, Wyka K, Melo B, Olden M, Jayasinghe N, Roberts J, Giosan C, Crane M, Difede J. 2011. The longitudinal course of PTSD among disaster workers deployed to the World Trade Center following the attacks of September 11th. J Trauma Stress 24:506-514.

Dirkzwager AJE, van der Velden PG, Grievink L, Yzermans CJ. 2007. Disaster-related posttraumatic stress disorder and physical health. Psychosom Med 69:435-440. 
Fagan J, Galea S, Ahern J, Bonner S, Vlahov D. 2003. Relationship of self-reported asthma severity and urgent health care utilization to psychological sequelae of the September 11, 2001 terrorist attacks. Am J Epidemiol 158:514-524.

Farfel M, DiGrande L, Brackbill R, Prann A, Cone J, Friedman S, Walker DJ, Pezeshki G, Thomas P, Galea S, Williamson D, Frieden TR, Thorpe L. 2008. An overview of $9 / 11$ experiences and respiratory and mental health conditions among World Trade Center Health Registry enrollees. J Urban Health 85:880-909.

Friedman SM, Maslow CB, Reibman J, Pillai PS, Goldring RM, Farfel MR, Stellman SD, Berger KI. 2011. Case-control study of lung function in World Trade Center Health Registry area residents and workers. Am J Respir Crit Care Med 184:582-589.

Galea S, Ahern J, Resnick H, Kilpatrick D, Bucuvalas M, Gold J, Vlahov D. 2002. Psychological sequelae of the September 11 terrorist attacks in New York City. N Engl J Med 346:982-987.

Global Initiative for Asthma. Pocket Guide for Asthma Management and Prevention, updated 2011. Available at http://www.ginasthma.org/ uploads/users/files/GINA_Pocket_April20.pdf. Accessed September 5, 2012

Goodwin RD, Fischer ME, Goldberg J. 2007. A twin study of posttraumatic stress disorder symptoms and asthma. Am J Respir Crit Care Med 176:983-987.

Gross R, Neria Y, Tao XG, Massa J, Ashwell L, Davis K, Geyh A. 2006. Posttraumatic stress disorder and other psychological sequelae among World Trade Center clean up and recovery workers. Ann NY Acad Sci 1071:495-499.

Herbert R, Moline J, Skloot G, Metzger K, Baron S, Luft B, Markowitz S, Udasin I, Harrison D, Stein D, Todd A, Enright P, Stellman JM, Landrigan PJ, Levin SM. 2006. The World Trade Center disaster and the Health of workers: Five-year assessment of a unique medical screening program. Environ Health Perspect 114:1853-1858.

Jordan HT, Miller-Archie SA, Cone JE, Morabia A, Stellman SD. 2011. Heart disease among adults exposed to the September 11, 2001 World Trade Center disaster: Results from the World Trade Center Health Registry. Prev Med 53:370-376.

Kessler RC, Andrews G, Colpe LJ, Hiripi E, Mroczek DK, Normand SLT, Walters EE, Zaslavsky AM. 2002. Short screening scales to monitor population prevalences and trends in non-specific psychological distress. Psychol Med 32:959-976.

Li J, Brackbill RM, Stellman SD, Farfel MR, Miller-Archie SA, Friedman S, Walker DJ, Thorpe LE, Cone J. 2011. Gastroesophageal reflux symptoms and comorbid asthma and posttraumatic stress disorder following the 9/11 terrorist attacks on World Trade Center in New York City. Am J Gastroenterol 106:1936-1944.

Luft BJ, Moline J, Pietrzak RH, Reissman D, Schecter C, Southwick SM, Udasin I, Friedman-Jimenez G, Guerrera K, Harrison D, Kotov R, Bromet EJ. 2012. Exposure, probable PTSD and lower respiratory illness among World Trade Center rescue, recovery and clean-up workers. Psychol Med 42(5):1069-1079.

Maslow CB, Friedman SM, Pillai PS, Reibman J, Berger KI, Goldring R, Stellman SD, Farfel M. 2012. Chronic and acute exposures to the world trade center disaster and lower respiratory symptoms: Area residents and workers. Am J Public Health 102(6):1186-1194.

Nair HP, Ekenga CC, Cone JE, Brackbill RM, Farfel MR, Stellman SD. 2012. Co-occurring lower respiratory symptoms and posttraumatic stress disorder 5 to 6 years after the World Trade Center Terrorist Attack. Am J Public Health 102(10):1964-1973.

Niles JK, Webber MP, Gustave J, Cohen HW, Zeig-Owens R, Kelly KJ, Glass L, Prezant DJ. 2011. Comorbid trends in World Trade Center Cough Syndrome and Probable Posttraumatic stress disorder in firefighters. Chest 140:1146-1154.

O'Toole BI, Catts SV. 2008. Trauma, PTSD, and physical health: An epidemiological study of Australian Vietnam veterans. J Psychosom Res 64(1):33-40.

Perlman SE, Friedman S, Galea S, Nair HP, Eros-Sarnyai M, Stellman SD, Hon J, Greene CM. 2011. Short-term and medium-term health effects of 9/11. Lancet 378:925-934.

Perrin MA, DiGrande L, Wheeler K, Thorpe L, Farfel M, Brackbill R. 2007. Differences in PTSD prevalence and associated risk factors among World Trade Center disaster rescue and recovery workers. Am J Psychiatry 164:1385-1394.

Ruggiero KJ, Ben KD, Scotti JR, Rabalais AE. 2003. Psychometric properties of the PTSD Checklist-Civilian version. J Trauma Stress 16 (5):495-502.

Stellman JM, Smith RP, Katz CL, Sharma V, Charney DS, Herbert R, Moline J, Luft BJ, Markowitz S, Udasin I, Harrison D, Baron S, Landrigan PJ, Levin SM, Southwick S. 2008. Enduring Mental Health Morbidity and social function impairment in World Trade Center rescue, recovery, and clean-up workers: The psychological dimension of an environmental health disaster. Environ Health Perspect 116:1248-1253.

Wagner AW, Wolfe J, Rotnitsky A, Proctor SP, Erickson DJ. 2000. An investigation of the impact of posttraumatic stress disorder on physical health. J Trauma Stress 13:41-55.

Weisberg RB, Bruce SE, Machan JT, Kessler RC, Culpepper L, Keller MB. 2002. Nonpsychiatric illness among primary care patients with trauma histories and posttraumatic stress disorder. Psychiatr Serv $53: 848-854$.

Wheeler L, McKelvey W, Thorpe L, Perrin M, Cone J, Kass D, Farfel M, Thomas P, Brackbill R. 2007. Asthma diagnosed after 11 September 2001 among rescue and recovery workers: Findings from the World Trade Center Health Registry. Environ Health Perspect 115:1584-1590.

Wisnivesky JP, Teitelbaum SL, Todd AC, Boffetta P, Crane M, Crowley L, de la Hoz RE, Dellanbaugh C, Harrison D, Herbert R, Kim H, Jeon Y, Kaplan J, Katz G, Levin S, Luft B, Markowitz S, Moline JM, Ozbay F, Pietrzak RH, Shapiro M, Sharma V, Skloot G, Southwick S, Stevenson LA, Udasin I, Wallenstein S, Landrigan PJ. 2011. Persistence of multiple illnesses in World Trade Center rescue and recovery workers: A cohort study. Lancet 378:888-897.

Wright RJ, Rodriquez M, Cohen S. 1998. Review of psychosocial stress and asthma: An integrated biopsychosocial approach. Thorax 53:1066-1074.

Zahran HS, Kobau R, Moriarty DG, Zack MM, Holt J, Donehoo R. 2005. Health-related quality of life surveillance-United States, 19932002. MMWR Surveill Summ 54(4):1-35. 